\title{
DESAIN KOMUNIKASI VISUAL SEBAGAI SARANA PROMOSI PERGURUAN TINGGI
}

\author{
Dewi Immaniar ${ }^{1}$ \\ Reni Mulyani ${ }^{2}$ \\ Fitria Arnita $^{3}$ \\ Dosen Jurusan Manajemen Informatika AMIK Raharja Informatika ${ }^{1}$,Alumni STMIK Raharja Jurusan \\ Teknik Informatika ${ }^{2}$, Mahasiswa STMIK Raharja Jurusan Sistem Informasi ${ }^{3}$ \\ dewi.immaniar@raharja.info; reni.mulyani@raharja.info; fitria.arnita@raharja.info
}

Diterima: 7 Juni 2017/ Disetujui : 14 Juni 2017

\begin{abstract}
Visual Communication Design as a Promotion Tool is a project that tries to describe a process of media design to inform a message regarding the promotion of an institution that is engaged in education that is STKIP Pasundan. Selection STKIP Pasundan is based on the consideration that this educational institution has great potential to compete with other similar educational institutions engaged in the field of College of Teacher Training and Education. Almost all educational institutions engaged in teacher training have the same facilities make the competition more difficult. Educational institutions that have long standing really have to be clever in attracting students to stay active and prospective students increase along with the many educational institutions that stand. Visual Communication Design is an appropriate means of promotion in building the identity of STKIP Pasundan to be able to compete and have a good image among the community. The basic design concept used is the simplicity / simplicity with the green color identity that is always applied in every design design. This concept is a simple concept that is able to attract attention. Seeing the conditions and problems, designed a visual communication design that can function effectively and variably that can convey information about STKIP Pasundan profile in detail and creative until the community and work relations image STKIP Pasundan Cimahi can be a positive recognition.
\end{abstract}

Keywords: Design, Promotion, Visual Communication

\begin{abstract}
ABSTRAK
Desain Komunikasi Visual Sebagai Sarana Promosi merupakan sebuah project yang mencoba memaparkan sebuah proses perancangan media untuk menginformasikan suatu pesan berkenaan dengan upaya promosi sebuah institusi yang bergerak dalam bidang pendidikan yaitu STKIP Pasundan. Pemilihan STKIP Pasundan ini didasari atas pertimbangan bahwa institusi pendidikan ini memiliki potensi yang besar untuk bersaing dengan institusi pendidikan sejenis lainnya yang bergerak di bidang Sekolah Tinggi Keguruan dan Ilmu Pendidikan. Hampir seluruh institusi pendidikan yang bergerak dibidang keguruan memiliki fasilitas yang sama membuat persaingan semakin sulit. Institusi pendidikan yang telah lama berdiri benar-benar harus pandai dalam menarik mahasiswa agar tetap aktif dan calon mahasiswa bertambah seiring dengan banyaknya institusi pendidikan yang berdiri. Desain Komunikasi Visual merupakan sebuah sarana promosi yang tepat dalam membangun identitas diri dari STKIP Pasundan untuk dapat bersaing dan memiliki citra yang baik dikalangan masyarakat. Konsep dasar perancangan yang digunakan adalah kesederhanaan/ simplicity dengan identitas warna hijau yang selalu diterapkan disetiap rancangan design. Konsep ini merupakan konsep yang bergaya sederhana namun mampu menarik perhatian. Melihat kondisi dan permasalahan, dirancang suatu desain komunikasi visual yang dapat berfungsi efektif dan variatif yang dapat menyampaikan informasi tentang profil STKIP Pasundan secara detail dan kreatif hingga kalangan masyarakat dan relasi kerja citra STKIP Pasundan Cimahi dapat pengakuan secara positif.
\end{abstract}

Kata kunci: Desain, Promosi, Komunikasi Visual 


\section{PENDAHULUAN}

Saat ini keterbukaan akses informasi memungkinkan informasi dapat dengan mudah diperoleh kapanpun dan dimanapun. Salah satunya penyebaran informasi dalam bidang pendidikan karena melihat pentingnya pendidikan bagi kehidupan masyarakat. Banyaknya lembaga pendidikan yang ada di Indonesia mewajibkan lembaga pendidikan tersebut menginformasikan keunggulankeunggulan yang ada dari berbagai disiplin ilmu pengetahuan, jurusan maupun jenjang pendidikan telah dipersiapkan oleh lembaga pendidikan tersebut. Kita menyadari sampai saat ini persaingan penyelenggaraan bidang pendidikan semakin marak diwarnai dengan mengedepankan kualitas dan status yang diperoleh yang nantinya masyarakatlah yang menilai lembaga pendidikan mana yang mempunyai kualitas pendidikan yang unggul sesuai dengan kebutuhan lingkungan kerja.

Sarana multimedia sebagai alat komunikasi mempunyai peranan yang sangat penting dalam menginformasikan sesuatu kepada masyarakat, hal ini dinilai sangat komunikatif dan efektif disaat mobilitas manusia yang semakin tinggi sehingga dibutuhkan bentuk media komunikasi yang menarik dan lebih interaktif yang ditujukan kepada masyarakat, dan banyak cara untuk menyampaikan suatu informasi yang diolah ke dalam bentuk multimedia agar terlihat lebih menarik dalam penyampaiannya.

Sekolah Tinggi Keguruan dan Ilmu Pendidikan (STKIP) Pasundan Cimahi adalah suatu lembaga pendidikan yang bertujuan untuk membina mahasiswa menjadi guru yang profesional dan tenaga kerja kependidikan lainnya. STKIP Pasundan Cimahi menawarkan berbagai program pendidikan dari jenjang pendidikan Program Studi Strata I yang diberikan, antara lain: Program Studi Strata I (SI) Jurusan Pendidikan Jasmani Kesehatan dan Rekreasi ( terakreditasi B ), Jurusan Pendidikan Bahasa Inggris (terakreditasi B), Jurusan pendidikan Pancasila dan Kewarganegaraan ( terakkreditasi B ), dan Program Studi Magister (S2) Jurusan Pendidikan Ilmu Pengetahuan Sosial ( terakreditasi B )

Saat ini STKIP Pasundan Cimahi menggunakan media promosi dan informasi dalam bentuk media cetak saja yaitu masih berupa spanduk, brosur, dan melakukan pemasaran dengan memperlihatkan foto-foto portfolio dan fasilitas yang belum dikemas dan tidak terorganisair dengan baik. Dalam mengembangkan usahanya di bidang pendidikan saat ini STKIP Pasundan Cimahi sangat membutuhkan sarana media penyampaian informasi dan promosi yang mampu mengemas seluruh aset yang dimiliki oleh STKIP Pasundan Cimahi untuk nantinya dijadikan sebagai media promosi kepada masyarakat untuk menarik minat calon mahasiswa baru dan juga menjalin kerjasama baik dengan intansi atau lembaga terkait.

Design Komunikasi Visual yang bersifat sebagai ujung tombak dalam kegiatan promosi. Booklet adalah media komunikasi massa yang bertujuan untuk menyampaikan pesan yang bersifat promosi, anjuran, larangan-larangan kepada khalayak massa dan berbentuk cetakan. Sehingga akhir dari tujuannya tersebut adalah agar masyarakat yang sebagai obyek memahami dan menuruti pesan yang terkandung dalam media komunikasi massa tersebut. Adapun keunggulan-keunggulan booklet adalah bahwa booklet ini menggunakan media cetak sehingga biaya yang dikeluarkannya itu bisa lebih murah jika dibandingkan dengan menggunakan media audio dan visual serta juga audio visual. Proses booklet agar sampai kepada obyek atau masyarakat bisa dilakukan sewaktu-waktu. Proses penyampaiannya juga bisa disesuaikan dengan kondisi yang ada, lebih terperinci dan jelas, karena lebih banyak bisa mengulas tentang pesan yang disampaikannya.

\section{PERMASALAHAN}

Bagaimana media visual yang berjalan pada STKIP Pasundan Cimahi pada saat ini ?; Apakah media visual yang berjalan pada saat ini sudah memenuhi kriteria sebagai media promosi dan informasi pada STKIP Pasundan Cimahi yang menarik dan meningkatkan citra STKIP Pasundan Cimahi ?; Bagaimana merancang media komunikasi visual sebagai media promosi yang efektif dan efisien ?

\section{LITERATURE REVIEW}

Literature Review adalah deskripsi hasil tinjauan pustaka yang dilakukan oleh peneliti terhadap hasil penelitian yang telah ada dan dilakukan oleh peneliti lain mengenai objek atau tema yang sejenis dengan topik yang hendak diteliti atau dibahas pada sebuah penelitian.

Literature review merupakan landasan awal dan pendukung bagi penelitian yang akan dilakukan oleh peneliti sehingga menghindari pengulangan membuat hal yang sama dan melakukan pengembangan 
ketingkat yang lebih tinggi dalam rangka menyempurnakan atau melengkapi hal penelitian yang sudah ada sebelumnya.

Dari beberapa hasil tinjauan dari perpustakaan raharja penulis mendapatkan beberapa Literature riview, di antaranya sebagai berikut :

a. " $\quad$ Perancangan Media Promosi dan Informasi tentang Perguruan Tinggi Raharja Semester Genap T.A 2008/2009”. Penelitian ini diambil dari laporan mahasiswa yang telah melaksanakan penelitian dan mempunyai kesamaan dalam topic atau pembahasan mengenai Design Komunikasi Visual . Adapun laporan yang telah diteliti adalah Media Informasi Visual dan promosi yang ada pada Perguruan Tinggi Raharja dapat dikatakan masih kurang lengkap, Perguruan Tinggi Raharja selalu membutuhkan sarana media komunnikasi visual sebagai penunjang media informasi dan promosi tersebut.

b. "Perancangan Design Komunikasi Visual Sebagai Media Promosi dan Informasi yang di Bentuk Dalam Buku Pada PT. Lakindo". Penelitian ini di ambil dari laporan yang ada di internet yang telah melaksanakan penelitian dan mempunyai kesamaan atau pembahasan mengenai Design Komunikasi Visual . Adapun laporan yang telah diteliti adalah media promosi dan informasi yang ada pada PT.LAKINDO dapat dikatakan masih kurang lengkap. PT. LAKINDO membutuhkan sarana media massa sebagai penunjang suksesnya event tersebut.

c. "Perancangan Buku Design Komunikasi Visual Sebagai Penunjang Media Promosi dan Informasi pada CV. Nani Budi Wedding Organizer”. Penelitian ini di ambil dari laporan yang ada di internet yang telah melaksanakan penelitian dan mempunyai kesamaan atau pembahasan mengenai Design Komunikasi Visual. Adapun laporan yang telah diteliti adalah media promosi dan informasi yang ada pada CV. Nani Budi Wedding Organizer membutuhkan media informasi sebagai sarana untuk memperkenalkan aset-aset yang dimiliki perusahaan kepada konsumen dan relasi bisnis khususnya yang melakukan kerjasama dalam bidang jasa wedding organizer.

d. "Perancangan Media Design Komunikasi Visual Sebagai Penunjang Informasi Dan Promosi Pada Cv. Zachra Utama Makmur Tangerang” disusun oleh Luthfi Pratama. Media penunjang informasi dan promosi sangat penting dalam membangun image dari sebuah lembaga atau institusi, salah satunya adalah media Design Komunikasi Visual . Fungsi media Design Komunikasi Visual secara umum adalah selain sebagai aset perusahaan juga berfungsi sebagai tanda atau identitas dari perusahaan dalam menjalin kerjasama dengan relasi yang baik dengan perusahaan atau lembaga dan instansi terkait lainnya. Penelitian ini bertujuan untuk menerapkan konsep media Design Komunikasi Visual dapat memberikan informasi dan promosi yang lebih efektif mengenai profil dan aktivitas perusahaan.

e. $\quad$ "Enriching Design Komunikasi Visual Sebagai Penunjang Informasi Dan Promosi Pada PT. T-Design Multikreasi” disusun oleh Achmad Zainudin M.N. Berkembangnya informasi dan komputer pada era globalisasi dewasa ini mengalami kemajuan yang sangat pesat terutama di bidang digital printing. Sehingga berpengaruh pada setiap aspek kehidupan masyarakat dalam Perkembangan bisnis di era globalisasi yang berkembang sangat pesat. Perusahaan-perusahaan saling bersaing untuk meningkatkan profitnya berbagai informasi dan promosi di galakan untuk menarik kepercayaan masyarakat, namun tanpa di dasari informasi yang komplit dan terpercaya mengenai profil perusahaan image PT.T-Design sulit tumbuh di masyarakat dalam hal ini konsumen dan klien.

PEMBAHASAN

Dari keseluruhan proses yang digunakan, diharapkan dapat memberikan banyak manfaat baik bagi STKIP Pasundan Cimahi maupun masyarakat luas. Pembuatan media visual Design Komunikasi Visual pada STKIP Pasundan Cimahi bertujuan untuk meningkatkan minat sasaran untuk bergabung di STKIP Pasundan Cimahi dengan tujuan penyampaian informasi yang efektif dan efisien.

\section{Market Analisis}

Market Positioning

Sekolah Tinggi Keguruan Dan Ilmu Pendidikan (STKIP) Pasundan Cimahi adalah suatu lembaga pendidikan yang bertujuan untuk membina mahasiswa menjadi guru yang profesional dan tenaga kerja kependidikan lainnya. STKIP Pasundan Cimahi terletak di Jl. Permana No. 32 B Tlp. (022) 6630345 Kota Cimahi 40512 dengan website www.stkippasundan.ac.id .

Konsumen STKIP Pasundan Cimahi itu sendiri adalah para siswa- siswi SMU atau sederajat yang telah menyelesaikan pendidikannya dan masyarakat umum yang menyadari akan pentingnya 
sebuah pendidikan dalam menghadapi era globalisasi. Dalam target marketing STKIP Pasundan CImahi melakukan segmentasi pasar yaitu mengidentifikasi dan membentuk kelompok konsumen (mahasiswa baru, relasi bisnis dan organisasi maupun masyarakat umum) yang terpisah-pisah yang mungkin membutuhkan bentuk pemasaran tersendiri, kemudian memilih satu atau lebih segment yang dianggap paling potensial dan menguntungkan serta mengembangkan program promosi yang dirancang khusus untuk segmen-segmen yang dipilih tersebut.

Dalam pendistribusian Design Komunikasi Visual yang sudah berbentuk booklet akan disampaikan pada acara-acara kegiatan kampus dan sebagai media promosi dan informasi bagi masyarakat umum. Bagi STKIP Pasundan Cimahi, media promosi ini sebagai alat pelengkap penyampaian informasi setelah brosur dan spanduk-spanduk yang telah ada saat ini, yang dapat didistribusikan kepada khalayak sasaran.

Kondisi Tentang Lembaga atau Perusahaan Pesaing

Pesaing STKIP Pasundan Cimahi antara lain dari perguruan-perguruan tinggi berbasis pendidikan dan perguruan-perguruan tinggi umum yang terdapat pada wilayah Bandung, antara lain:

Tabel 1. Tabel Pesaing

\begin{tabular}{|c|c|c|c|c|}
\hline No. & $\begin{array}{l}\text { Nama } \\
\text { Lembaga }\end{array}$ & Alamat & Fakultas dan Kejurusan & $\begin{array}{l}\text { Kegiatan Promosi yang } \\
\text { dilakukan }\end{array}$ \\
\hline 1. & $\begin{array}{l}\text { Universitas } \\
\text { Bale } \\
\text { Bandung }\end{array}$ & $\begin{array}{lr}\text { Jl. } & \text { R.A.A } \\
\text { Wiranatakusumah } \\
\text { No.7 } & \text { Baleendah } \\
40375 & \text { Kabupaten } \\
\text { Bandung } & \end{array}$ & $\begin{array}{l}\text { Pendidikan Geografi, Pendidikan Bahasa } \\
\text { Inggris, Pendidikan Bahasa Indonesia dan } \\
\text { Sastra Daerah, Pendidikan IPS }\end{array}$ & Brosur, pamphlet \\
\hline 2. & $\begin{array}{l}\text { Universitas } \\
\text { Pendidikan } \\
\text { Indonesia }\end{array}$ & $\begin{array}{l}\text { Jl. Dr. Setiabudhi No. } \\
229 \text { Bandung } 40154 \\
\text { Jawa Barat - } \\
\text { Indonesia }\end{array}$ & $\begin{array}{l}\text { Fakultas Ilmu Pendidikan (FIP), Fakultas } \\
\text { Pendidikan Ilmu Pengetahuan Sosial (FPIPS), } \\
\text { Fakultas Pendidikan Bahasa dan Seni (FPBS), } \\
\text { Fakultas Pendidikan Matematika dan IPA } \\
\text { (FPMIPA), Fakultas Pendidikan Teknologi } \\
\text { dan Kejuruan, Fakultas Pendidikan Olahraga } \\
\text { dan Kesehatan (FPOK), Fakultas Pendidikan } \\
\text { Ekonomi dan Bisnis (FPEB). }\end{array}$ & $\begin{array}{l}\text { Melakukan kegiatan } \\
\text { promosi dengan } \\
\text { memberikan poster } \\
\text { kesekolah-sekolah } \\
\text { SMU/sederajat dan } \\
\text { sepanduk pada jalan- } \\
\text { jalan tertentu. }\end{array}$ \\
\hline 3. & $\begin{array}{l}\text { FKIP Uninus } \\
\text { Bandung }\end{array}$ & $\begin{array}{l}\text { Jl.Soekarno Hatta no. } \\
530 \text { Bandung } 40286 \\
\text { Jawa Barat }\end{array}$ & $\begin{array}{l}\text { Program Studi Pendidikan Luar Sekolah, } \\
\text { Program Studi Pendidikan Luar Biasa, } \\
\text { Program Studi Pendidikan Bahasa dan Sastra } \\
\text { Indonesia, Program Studi Pendidikan Bahasa } \\
\text { Inggris, Program Studi Pendidikan Bahasa } \\
\text { Arab, Program Studi Pendidikan Matematika, } \\
\text { Program Studi Pendidikan Pancasila dan } \\
\text { Kewarganegaraan, Pendidikan Guru PAUD }\end{array}$ & $\begin{array}{l}\text { Melakukan kegiatan } \\
\text { promosi melalui media } \\
\text { cetak berupa brosur }\end{array}$ \\
\hline
\end{tabular}

\section{Potensial Market}

STKIP Pasundan Cimahi memfokuskan pemasaran pada sekitar wilayah Bandung, sasaran yang dituju adalah siswa siswi SMA atau Sederajat yang telah lulus. Jika ditinjau dari tujuan promosi ini adalah untuk mengarahkan seseorang agar dapat mengenal profil STKIP Pasundan Cimahi, lalu memahaminya dan berubah sikap, menyukai, yakin, kemudian akhirnya menjadi calon mahasiswa STKIP Pasundan Cimahi. Hal ini, dapat meningkatkan jumlah permintaan akan suatu media informasi dan promosi STKIP Pasundan Cimahi untuk memperkenalkan dan memberi pemahaman tentang profil STKIP Pasundan Cimshi (calon mahasiswa baru, relasi dan masyarakat). Oleh sebab itu, divisi marketing menginformasikan pada tahun 2012 jumlah penerimaan mahasiswa baru mencapai 670 mahasiswa, namun untuk tahun 2013 ini divisi marketing mentargetkan jumlah penerimaan mahasiswa baru mencapai 950 calon mahasiswa baru. Potensial market STKIP Pasundan Cimahi lebih ke lokasi Cimahi dan Bandung.

\section{Market Segmentation}

Geografi

: Wilayah Kabupaten dan Kota Bandung, Kota Cimahi serta Propinsi Jawa

Barat.

Demografi

- Jenis Kelamin

Pria \& Wanita 
- Kelas Ekonomi

- Sasaran
Menengah

1. Siswa-siswi SMA

2. Karyawan/i

3. Khalayak (masyarakat)

Psikografi : Masyarakat yang peduli akan pentingnya pendidikan dan ingin melanjutkan kuliah di STKIP Pasundan Cimahi.

\section{Marketing Objective (Tujuan Pemasaran)}

Tujuan pemasaran dari Design Komunikasi Visual yang dibuat yaitu untuk mengarahkan seseorang agar dapat mengenal STKIP Pasundan Cimahi, lalu memahaminya, berubah sikap, menyukai, kemudian akhirnya menjadi bergabung untuk menjadi mahasiswa STKIP Pasundan Cimahi. Dalam memberikan media informasi dan promosi tentang profil STKIP Pasundan Cimahi kepada konsumen (calon mahasiswa baru, relasi maupun masyarakat) divisi marketing menambah sarana promosi, yaitu dengan media Design Komunikasi Visual karena media informasi promosi yang digunakan sebelumnya (brosur) masih kurang lengkap, oleh sebab itu media Design Komunikasi Visual dirancang secara detail dan menarik agar dapat meningkatkan jumlah calon mahasiswa baru yang sesuai target dari divisi marketing sebanyak 950 orang untuk bergabung menjadi STKIP Pasundan Cimahi.

\section{Marketing Strategi (Strategi Pemasaran)}

STKIP Pasundan Cimahi adalah salah satu institusi pendidikan yang berada di wilayah Provinsi Jawa Barat adalah institusi pendidikan berbasis keguruan yang menawarkan berbagai program pendidikan. Hingga saat ini telah dipersiapkan berbagai hal yang dapat meningkatkan mutu pendidikan, dimana seluruh program studi yang ada di STKIP Pasundan Cimahi sudah terakreditasi dari BAN-PT dengan predikat terbaik. Oleh karena itu STKIP Pasundan Cimahi mempromosikan lembaga pendidikannya menggunakan media Design Komunikasi Visual sebagai penunjang promosi seperti menampilkan sejarah,visi dan misi, keunggulan dan prestasi serta hasil yang berhubungan dengan kualitas dari STKIP Pasundan Cimahi.

\section{Software Yang Digunakan}

Dalam Konsep media informasi dan promosi tersebut, penulis menggunakan software Adobe Photoshop Cs5 dan Adobe Illustrator Cs5. Adobe Illustrator CS5 adalah program grafis berbasis vektor yang paling tangguh dan populer, karena fasilitas-fasilitas di dalamnya dapat digunakan untuk membentuk objek secara tiga dimensi, sehingga hasil yang diperoleh menyerupai objek yang sebenarnya. Adobe Photoshop CS5 adalah suatu perangkat lunak canggih yang dapat anda gunakan untuk membuat, menyunting dan memanipulasi tampilan termasuk mengoreksi warnadan memberi efek tampilan atas sebuah gambar atau photo, hasil dari program ini merupakan sebuah gambar / image, di dalam komputer grafis terbagi menjadi 2 kelompok yaitu Gambar Bitmap dan Gambar Vektor.

Dalam hal ini, konsep media yang diajukan adalah perancangan Design Komunikasi Visual dalam bentuk sabuah booklet yang berukuran $59 \mathrm{~cm}$ x $21 \mathrm{~cm}$. Design Komunikasi Visual ini berisi tentang profil dari STKIP Pasudan Cimahi, sejarah, visi dan misi, tujuan dan motto, status akreditasi, keunggulan STKIP Pasundan Cimahi, program studi yang ada di STKIP Pasundan Cimahi, organisasi kemahasiswaan, dan fasilitas yang terdapat pada STKIP Pasundan Cimahi. Semua isi yang terkait dalam pembuatan Design Komunikasi Visual tersebut dikemasdengan menggunakan pengembangan kreatif desain grafis.

\section{Tujuan Media}

Tujuan dari perancangan media Design Komunikasi Visual ini adalah sebagai salah satu sarana media informasi untuk mempromosikan aset-aset yang dimiliki oleh STKIP Pasundan Cimahi kepada masyarakat atau relasi kerja baik perguruan tinggi, perusahaan, maupun pemerintah.

Perancangan Design Komunikasi Visual ini harus menjangkau 80\% dari khalayak sasaran. Media informasi dan sarana komunikasi ini digunakan selama kondisi STKIP Pasundan Cimahi tidak mengalami perubahan baik strategi maupun manajemen. 


\section{Strategi Media}

Sebelum melakukan proses desain, penulis terlebih dahulu merumuskan strategi media. Dalam penjabaran media ada 2 syarat utama yang harus dipenuhi, yaitu : aspek khalayak sasaran dan media yang digunakan.

Dalam menunjang kelancaran melakukan strategi media informasi dan promosi adalah menggunakan media buku Design Komunikasi Visual , persiapan maupun jalanny promosi dari beberapa isi buku Design Komunikasi Visual yang akan digunakan secara visual ditampilkan terpadu (satu untuk semua) artinya tampilan setiap isi buku yang digunakan senada.

\section{Program Media}

Rencananya media informasi dan promosi ini mulai digunakan awal tahun 2014 dengan jadal promosi dalam jangka panjang yang disesuaikan dengan kondisi dan perkembangan dari STKIP Pasundan Cimahi.

\section{Perencanaan Pesan ( Konsep Kreatif )}

Konsep kreatif pada media Design Komunikasi Visual ini, penulis mencoba menuagkan ideidekreatif berdasarkan data-data obyek yang diperoleh dari STKIP Pasundan Cimahi, yang kemungkinan diolah dalam sebuah desain sesuai dengan alur proses kreatif yang ada pada setiap lembar halaman dan disesuaikan dengan kebutuhan STKIP Pasundan Cimahi.

Tujuan Kreatif

Hal-hal yang terdapat pada rancangan media yang berupa pengolahan warna, jenis huruf, ornamen, dan elemen lainnya bertujuan untuk mendapatkan harmonisasi dankeselarasan yang ada di tiap-tiap rancangan media, selain dinilai dari segi fungsi juga terdapat nilai-nilai artistik yang dapat menarik minat masyarakat ataupun relasi kerja.

\section{Strategi Kreatif}

Hal yang ingin disampaikan kepada masyarakat dan relasi kerja melalui visualisasi yang terdapat pada perancangan media informasi dan promosi adalah hal yang dapat menunjukan eksistensi dari STKIP Pasundan Cimahi sebagai salah satu institusi yang bergerak dibidang pendidikan dengan cara menampilkan keunggulan dan kualitas dari STKIP Pasundan Cimahi.

\section{Perancangan Visual}

Design Komunikasi Visual yang ingin disampaikan oleh penulis yaitu kesan yang harmonis,ekslusif, dan colorfull diantaranya tata letak (layout), warna, tipografi, dan gambar.

Penyajian desain Design Komunikasi Visual dengan tetap mempertahankan warna ciri khas dari STKIP Pasundan Cimahi yang diolah dengan kombinasi warna lain yang senada dengan warna asli tersebut. Untuk gambar, penulis menggunakan gambar-gambar yang penulis ambil sendiri maupun gambar yang diperoleh dari data yang sudah ada dari setiap kegiatan yang dilaksanakan oleh STKIP Pasundan Cimahi, yang diolah dengan menggunakan gabungan beberapa software pendukung yaitu : Adobe Photoshop, Adobe Ilustrator dan software pendukung lainnya sebagai sarana dalam menyampaikan strategi kreatif.

\section{Tujuan Visual}

Tujuan visualisasi dalam desain Design Komunikasi Visual adalah untuk mempengaruhi minat masyarakat untuk dapat membaca, mengerti ataupun memahami seluruh informasi yang dimuat dalam media Design Komunikasi Visual . Sedangkan dengan dibuatnya Design Komunikasi Visual citra yang ditampilkan yaitu dapat menciptakan suatu identitas yang baik dan menjadi institusi pendidikan yang lebih dipercaya eksistensinya oleh masyarakat dan relasi kerja dari STKIP Pasundan Cimahi sehingga dapat menimbulkan citra baru yang baik bagi STKIP Pasundan Cimahi sebagai sebuah institusi yang bergerak di bidang pendidikan. Proses desain Design Komunikasi Visual ini lebih ditekankan kepada hal-hal yang akan mempengaruhi hasil dari desain yang berkualitas baik serta mempunyai nilai seni yang tinggi dengan memperhatikan unsur warna yang dipilih, jenis huruf yang digunakan, tata letak atau layout yang diterapkan, gambar yang dipilih, dan ditampilkan dalam Design Komunikasi Visual . 


\section{Strategi Visual}

Penyajian visual pada perancangan media informasi yaitu dengan pembentukan obyek-obyek dan pengaturan tata letak dengan menggunakan adobe ilustrator dan adobe photoshop disesuaikan dengan kebutuhan rancangan. Adapun strategi visual yang ingin disampaikan penulis adalah dengan pendekatan secara emosional yang terkesan formal namun tegas mulai dari segi warna, layout, jenis huruf, dan gaya penampilan grafis dalam bentuk penyampaiannya dilakukan secara sederhana agar konsumen dan relasi bisnis lebih dapat memahami, dari pencitraan tersebut diharapkan dapat menarik minat masyarakat atau realsi kerja setelah mengetahui kelebihan-kelebihan melalui buku Design Komunikasi Visual ini.

\section{Penulisan Naskah (Copy Writing)}

Rancangan media visual Design Komunikasi Visual terdapat unsur-unsur komunikasi grafis seperti teks (tulisan), ilustrasi (foto atau gambar), dan warna. Salah satunya adalah teks (tulisan) yang mempunyai karakter khusus diperlukan dalam perancangan agar penyampaian misi media mudah dimegerti dan tepat sasaran, teks akan disesuaikan dengan bentuk-bentuk media yang telah direncanakan terdiri dari beberapa bagian yaitu judul (headline), subjudul, naskah (body copy), logo. Berikut adalah penjelasan dari masing-masing bagian dari teks (tulisan) : a.Judul (Headline) Bagian terpenting dari teks menarik perhatian dan merupakan hal yang pertama kali dibaca. Judul akan mengarahkan pembaca untk lebih jauh mengetahui tentang isi dari sebuah pesan atau informasi yang ada di dalamnya.b.Subjudul Lanjutan keterangan dari judul yang akan menjelaskan makna atau arti dari judul, pada umumnya subjudul akan lebih panjang dari judul. Subjudul dapat juga disebut sebagai kalimat peralihan yang mengarahkan pembaca dari judul ke kalimat pembukaan naskah (body copy).c. Naskah (body copy) d. Kalimat yang menerangkan lebih rinci tentang isi pesan yang ingin disampaikan, berfungsi untuk mengarahkan pembaca dalam mengambil sikap berpikir dan bertindak lanjut. Secara kreatif bentuk naskah atau body copy dapat dikombinasikan dengan gambar dalam berbagai betuk.e. LogoTanda pengenal atau identitas yang tetap dari sebuah perusahaan, institusi, atau lembaga biasanya dibuat secara singkat, sederhana dan komunikatif dengan menggunakan huruf atau gambar agar lebih mudah diingat. f. Kata Penutup (closing word). Kalimat pendek yang jelas, singkat, jujur, dan jernih yang biasanya bertujuan untuk mengarahkan pembaca membuat keputusan.

\section{Pengarahan Visualisasi (Art Direction)}

Agar desain media komunikasi visual yang dirancang terlihat menarik dan memiliki karakter tersendiri maka dalam proses visualisasi penulis harus memperhatikan al-hal yang akan mempengaruhi kegunaan dan nilai artistik sebuah media. Dalam menentukan unsur-unsur warna yang dipilih, jenis huruf yang dipakai, layout yang diterapkan, gaya penampilan grafis yang sesuai serta model yang dipilih untuk ditampilkan disetiap rancangan media. Oleh sebab itu, penulis menjabarkan visualisasi yang dipilih dan dapat dipergunakan pada media-media rancangan :

Warna yang dipergunakan adalah warna hijau dan orange, karena hijau menciptakan suasana alam yang sejuk dan asri, pertumbuhan, kesuburan, keremajaan, keyakinan, pengharapan, kesanggupan, kehidupan, penelitian sedangkan orange melambangkan kemajuan, semangat, perkembangan, energi sesuai dengan citra dari STKIP Pasundan Cimahi, Jenis huruf yang dipergunakan adalah jenis huruf karena jenis huruf tersebut berkesan teknologi, formal, dan mudahdibaca oleh setiap pembaca, Tata letak atau layout yang dipergunakan adalah dengan menata atau menyatukan unsur-unsur komunikasi visual mulai dari teks, gambar, dan warna agar menjadi media komunikasi visual yang komunkatif dan dapat menarik perhatian masyarakat dan relasi kerja, Gaya penampilan grafis yang dipergunakan adalah enciptakan kesan elegan tapi tegas dan dinamis, karena STKIP Pasundan Cimahi merupakan salah satu institusi yang bergerak di bidang pendidikan, Model yang dipergunakan dalam booklet Design Komunikasi Visual adalah gambar dan foto kegiatan yang diselenggarakan dan aset yang ada di STKIP Pasundan Cimahi karena untuk mewakili dari keterangan teks yang ada dalam booklet Design Komunikasi Visual agar masyarakat dan relasi kerja lebih mudah mengerti dan memahami dari isi informasi tersebut.

\section{Proses Desain (Designing)}

Dalam proses pembuatan booklet Design Komunikasi Visual ini, penulis melakukan secara bertahap sesuai dengan tahapan yang telah ditentukan melalui buku panduan, untuk mendapatkan hasil 
rancangan yang menarik dan efektif diterapkan tahapan Layout Kasar (Rough Layout) dan Layout Komprehensif. Layout Kasar (Rough Layout) ialah sebelum membuat rancangan melalui komputer, penulis terlebih dahulu membuat layout kasar dengan menggunakan alat gambar pensil dan kertas untuk memberikan kebebasan penulis dalam menuangkan ide gagasan yang sesuai dengan perancangan, selain itu sebagai pedoman pada saaat proses desain dengan menggunakan komputer. Proses-proses berikutnya, dalam hal ini yang dimaksud dengan layout kasar adalah penempatan elemen-elemen desain yang nantinya akan dipergunakan dalam perancangan media komunikasi visual yang disertai acuan standarisasi pada desain yang akan dbuat, umumnya dibuat hitam putih, salah satu diantaranya dapat dibuat dengan coretan atau sketsa dengan menggunakan pensil gambar. Pada tahap ini penulis akan menyesuaikan terhadap banyaknya jenis media yang akan dirancang dari media pertama hingga selanjutnya. Layout komprehensif adalah suatu gambar yang sudah mendekati komposisi gambar yang pada umumnya disajikan dalam bentuk warna dan disertaidengan deskripsi rancangan media.

\section{IMPLEMENTASI}

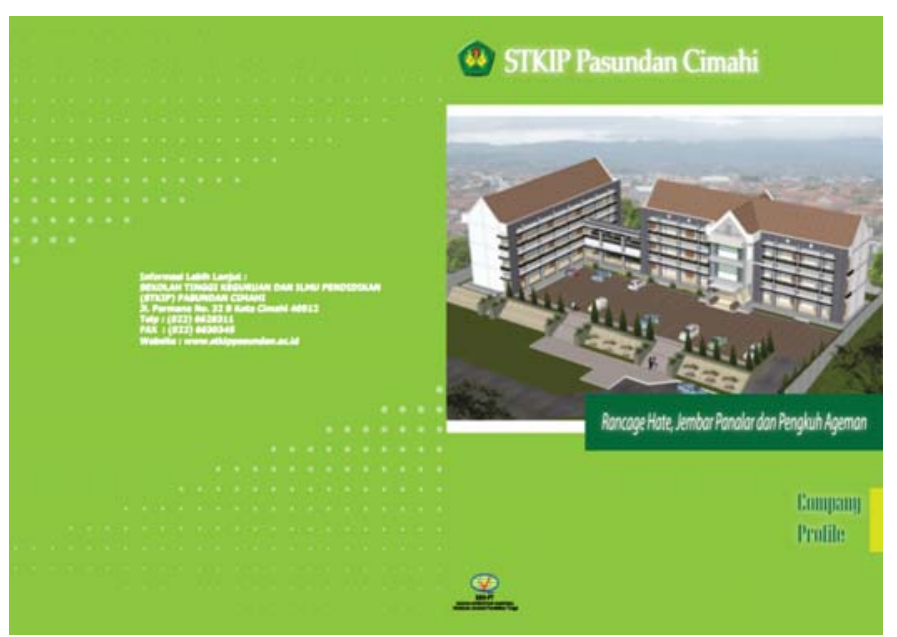

Gambar 1. Cover Design

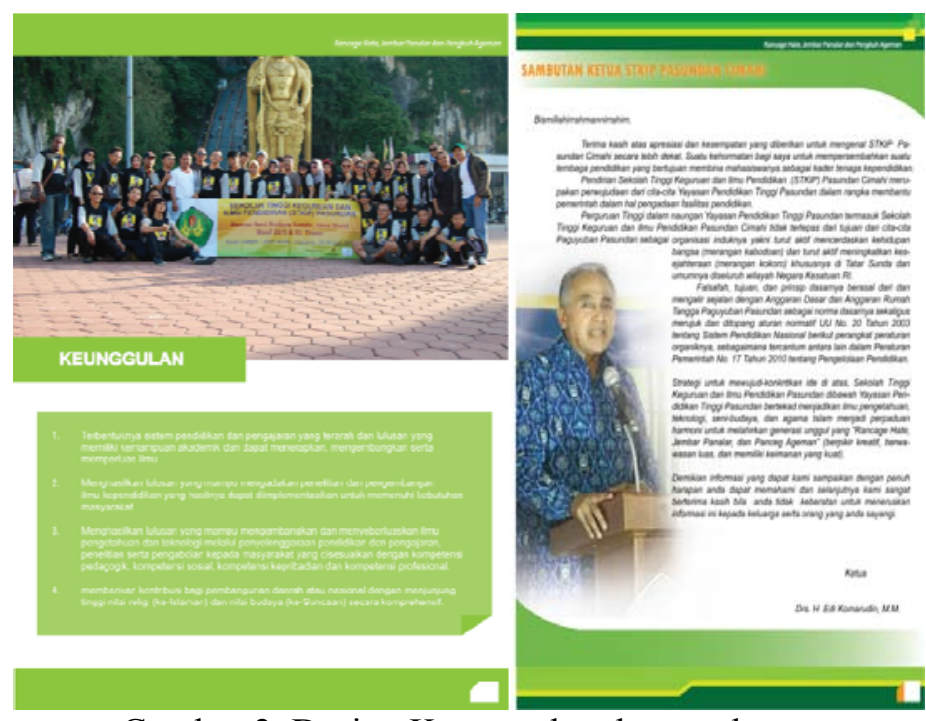

Gambar 2. Design Keunggulan dan sambutan 


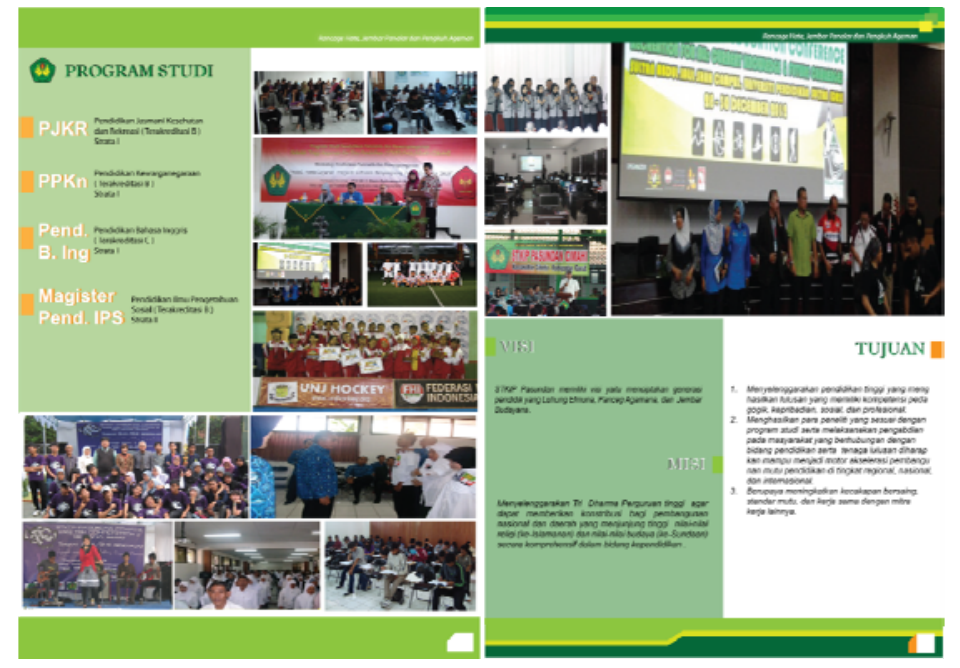

Gambar 3. Design Prodi dan VIsi Misi

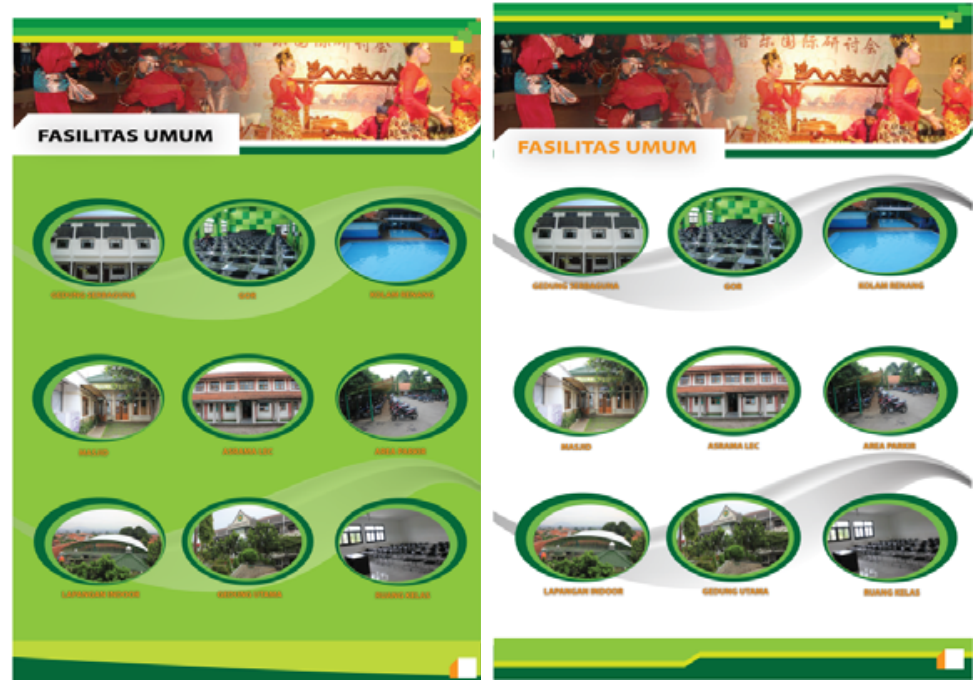

Gambar 4. Design Fasilitas-Fasilitas STKIP Pasundan

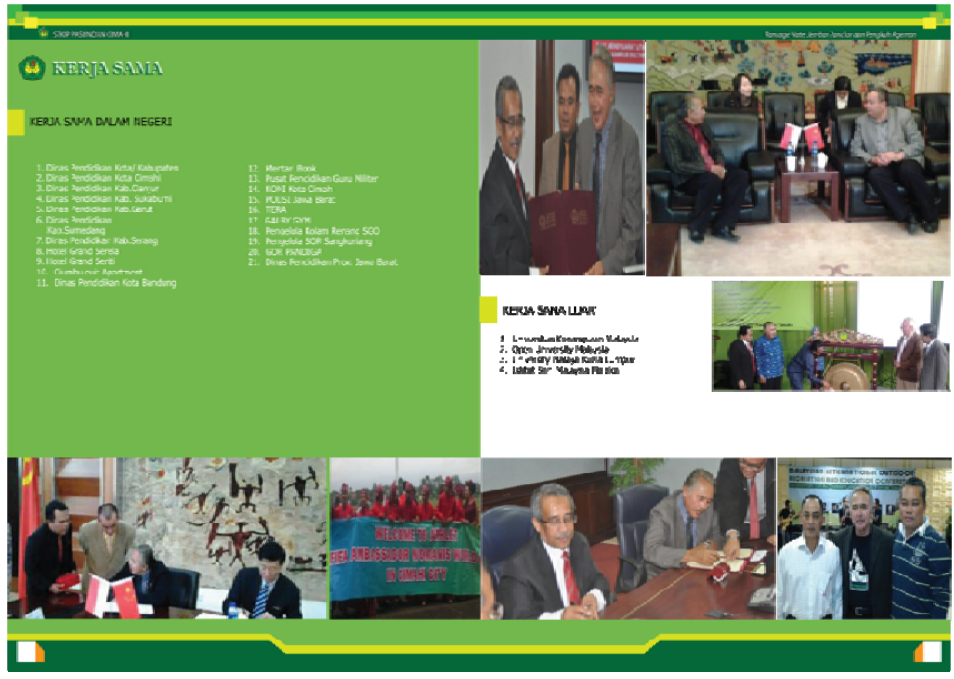

Gambar 5. Design Kerjasama Institusi 


\section{KESIMPULAN}

Media Design Komunikasi Visual di rancang dengan pertimbangan kaidah atau prinsip-prinsip dasar desain grafis dan dimaksimalkan dengan menggunakan aplikasi-aplikasi program komputer grafid akan menghasilkan bentuk media yang lebih menarik dan dapat lebih bermanfaat kepada pihak institusi yang membutuhkan. Melalui Design Komunikasi Visual berbentuk booklet yang dapat menyampaikan informasi tentang profil STKIP Pasundan Cimahi secara detail dan kreatif diharapkan di kalangan masyarakat dan relasi kerja citra STKIP Pasundan Cimahi dapat pengakuan secara positif. Design Komunikasi Visual yang dirancang dengan menggunakan komputer grafis dengan memperhatikan prinsip-prinsip dasar dalam rancangan media merupakan suatu cara untuk meningkatkan citra STKIP Pasundan Cimahi

\section{DAFTAR PUSTAKA}

[1] Agusrijanto, 2001. Copywriting seni mengasah Kreatifitas dan memahami bahasa iklan, Bandung: PT. Remaja Rosdakarya Offset.

[2] A.H. Maslow dalam tulisannya yang berjudul "Motivation and Personality".

[3] Alwi, Hasan. 2002. Kamus Besar Bahasa Indonesia. Jakarta; P.N. Balai Pustaka.

[4] Ananda, Maya. 1978. Seluk Beluk Reklame dalam Dunia Perdagangan. Jakarta:Mutiara

[5] Christofer Santosa. 2002. Layout-Dasar \& Penerapannya. Jakarta: Gramedia.

[6] Dalley, Terrence. 1983.The Complete Guide to Illustration and Design. London:Chartwells books.

[7] Dirjen Pariwisata. 1988 . Pariwisata Tanah air Indonesia.

[8] Hassan Shadily. 1984. Ichtiar Baru-Van Hoeve. Jakarta

[9] Komisi Periklanan Indonesia. 1996. Tata Krama dan Tata Cara PeriklananIndonesia yang Disempurnakan. Jakarta: Gedung Dewan Pers.

[10] Kusmiati, A, S. Pudjiastuti \& P. Suptandar. 1999. Teori Dasar Desain Komunikasi Visual. Jakarta: Djambatan

[11] Kartajaya,Herman. 2002. Mark Plus on Strategy. Jakarta: Gramedia Pustaka Utama.

[12] Nuradi. 1996. Kamus Istilah Periklanan Indonesia. Jakarta : PT GramediaPustaka Utama

[13] Pujiriyanto, 2005. Desain Grafis Komputer. Yogyakarta: Andi Yogyakarta

[14] Rhenald Kasali, 1997. Manajemen Periklanan. Jakarta: PAU-Ekonomi UI \& Grafiti Pers.

[15] Sanyoto, Ebdi Sadjiman. (2005). Dasar-Dasar Tata Rupa dan Desain (nirmana). Yogyakarta: CV. Arti Bumi Intaran.

[16] Scheder, Georg. 1977. Perihal Cetak Mencetak. Yogyakarta: Kanisius.

[17] Santosa, Sigit. 2002. Advertising Guide Book. Jakarta: PT Tarsito.

[18] Sachari, Agus. 1986. Paradigma Desain Indonesia. Jakarta : CV Rajawali

[19] Susanto, Astrid. 1986. Filsafat Komunikasi. Bandung : Bina Cipta

[20] Swann, Alan. 1987. Basic design and layout. Yogyakarta: Andi.

[21] Togama Naibaho dan Wegig Murwonogroho, (1998). Metodeloogi Riset Seni Rupa dan Desain. Jakarta: Universitas Trisakti.

[22] Wirya, Iwan. 1999. Kemasan Yang Menjual. Jakarta : PT Gramedia 